
\title{
Research S Surate \\ Gentian Violet modulates cytokines levels in mice spleen toward an anti-inflammatory profile
}

\section{Salam Jbeili}

University of Balamand

\section{Mohamad Rima}

Lebanese University: Universite Libanaise

Abdul Rahman Annous

University of Balamand

Abdo Ibrahim Berro

University of Balamand

\section{Ziad Fajloun}

Lebanese University

Marc Karam ( $\nabla$ marckaram1@gmail.com )

University of Balamand https://orcid.org/0000-0003-3897-8883

\section{Research}

Keywords: Gentian Violet, IFN-y, TNF-a, IL-1 $\beta$, IL-10, IL-4, IL-13

Posted Date: November 19th, 2020

DOI: https://doi.org/10.21203/rs.3.rs-108099/v1

License: (c) (1) This work is licensed under a Creative Commons Attribution 4.0 International License. Read Full License 


\section{Abstract}

Introduction: Gentian Violet (GV) is a triphenylmethane industrial dye that is known for its antibacterial, antiviral, anti-helminthic and anti-tumor effects. Although many studies focused on determining the biological and pharmacological applications of GV, its exact effect on the immune response has not been elucidated yet.

Methods: In this study, we investigate the immunomodulatory effects of GV in BALB/c mice after intraperitoneal injection of the dye by assessing cytokines levels in the spleen.

Results: Our data show that GV-treated mice have decreased level of proinflammatory cytokines (IL-1 $\beta$ and TNF- $a$ ) and increased level of anti-inflammatory cytokines (IL-4) in their spleens. In addition, IFN- $\gamma$ that can modulate pro-inflammatory cytokine production was upregulated in GV-treated mice.

Conclusion: Together, these findings suggest an anti-inflammatory activity of GV that warrant further studies investigating the potential of GV in immunotherapy.

\section{Background}

Gentian Violet (GV) is a triphenylmethane dye used in industry for ink, sanitary products, ceramics and photo-imaging system [1,2]. The dye, discovered by Charles Lauth [3], is also used by scientists in different biological applications including bactericidal, antifungal and anthelminthic activities [4, 5]. In fact, GV was used in the treatment of skin burns, dermal and systemic Candidiasis. The molecule was recognized as an antiseptic of wounds and an inhibitor of mold in poultry. It is very beneficial against parasites such as cutaneous Leischmania and Chagas disease in the blood [6]. Gentian Violet was also known by its efficiency against gram positive organism [7] as well as Nipah and Hendra virus [8]. Despite of all its benefits, GV is toxic at high doses, and it cannot be managed easily [9-12] as it can be carcinogenic, and cause gastrointestinal side effects and taste alteration in human body $[13,14]$. Recent study showed that GV reduces the effect of angiopoetin-2 (ang-2), a proinflammatory receptors in angiogenesis [7], which suggest an immunomodulatory effect of the molecule. In agreement with this finding, GV inhibited the proliferation of breast cancer cells by suppressing the activity of the proinflammatory molecule NF-KB [15-17]. Gentian violet was also shown to inhibits reactive oxygen species (ROS), leading to the decline of the inflammatory activity of NF-kB $[18,19]$. In this study we investigated the immunomodulatory potential of GV in vivo. We show that GV has anti-inflammatory potential by downregulating proinflammatory cytokines (IL-1 $\beta$ and TNF- $\alpha$ ) and upregulating antiinflammatory cytokines (IL-4) and IFN- $y$ that modulates pro-inflammatory cytokine production.

\section{Materials And Methods}

\section{Gentian Violet}


Gentian Violet was supplied from Sigma Aldrich (G2039) in powder form and stored at room temperature. Gentian Violet was dissolved in PBS prior to the experiment and filtered through $0.2 \mu \mathrm{m}$ sterile syringe filters.

\section{Mice handling and treatment}

Eight to ten weeks old female BALB/c mice procured from the from the University of Balamand (UOB) animal house were used in this study. Animals were fed a standard diet and kept at $25^{\circ} \mathrm{C}$ in 12 hours day/night cycle and handled according to the Guide for Care and Use of Laboratory Animals of the UOB Faculty of Sciences. Mice were divided into two groups that were injected intraperitoneally with either Gentian Violet (5 mg/kg) or PBS (control). Each mouse underwent three injections with 48 hours (hrs) of interval between each injection. Mice were sacrificed $24 \mathrm{hrs}$ following the last injection by cervical dislocation. Spleens were removed, weighted, and then cut in half. For histology, spleen parts were reserved in chloroform at $-20^{\circ} \mathrm{C}$; while those for ELISA were kept in eppendorf tubes at $-80{ }^{\circ} \mathrm{C}$. All animals were handled and experimental procedures were carried out according to the guidelines of the Institutional Animal Care and Use Committee at the University of Balamand, with strict adherence to the ethical guidelines for the study of experimental pain in conscious animals [20].

\section{Histopathology}

Tissue for histopathology was processed as described in [21, 22]. Briefly, spleen samples were processed for dehydration, clearing, and impregnation by Leica TP1020 Tissue Processor. Paraffin blocks were prepared using ThermoFisher Histostar Tissue Embedding Station and serial sections of $3 \mu \mathrm{m}$ thickness were cut using Leica RM2255 Fully Automated Rotary Microtome. Sections were placed on slides with $50 \mathrm{mM}$ ethanol, then immerged in dissolved $0.1 \%$ gelatin. Dewaxing was performed by emerging the prepared slides $2 \times 5$ min in Xylol. Samples were then washed $3 \times 2$ min with $95 \%$ ethanol, then for 2 min with $75 \%$ ethanol, then $50 \%$ ethanol. Samples were drained for 3 min with water, treated with $0.37 \% \mathrm{HCL}$ in $70 \%$ ethanol to remove hemotoxylin excess, and redrained for 2 min with water. Nucleus was stained using ammonia, and cytoplasm was stained using eosin. Slides were washed $5 \times 10$ min with $95 \%$ ethanol, emerged in Xylol and mounted with coverslips. Mounted tissue sections were observed under Swift M2250 Series Monocular lab light microscope for structural changes and abnormalities.

\section{Tissue Homogenization and Protein Quantification}

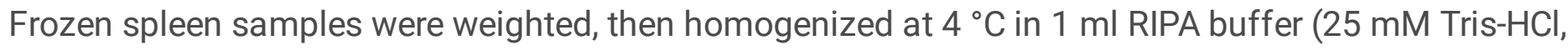
$150 \mathrm{mM} \mathrm{NaCl}, 1 \% \mathrm{NP}-40,1 \%$ sodium deoxycholate, $0.1 \%$ SDS pH = 7.6) supplemented with protease inhibitors. The homogenates were incubated on ice for 30 minutes and then centrifuged at $10000 \mathrm{~g}$ for 30 minutes at $4{ }^{\circ} \mathrm{C}$. Supernatants were transferred to labeled Eppendorf tubes and protein concentration of each sample was quantified using Bio-Rad Protein Assay kit according to the manufacturer's recommendations. Samples were stored at $-80^{\circ} \mathrm{C}$ for cytokine measurement.

\section{Cytokine Measurement}


Quantitative evaluation of cytokines was performed using Enzyme-Linked Immuno-Sorbent Assay (ELISA) Development Kits (Cat. \#900-K00, Peprotech) according to the manufacturer's recommendations. Briefly, $100 \mu \mathrm{l}$ of prepared supernatants/standards were added into the 96-well plates in duplicates. Plates were read with an ELISA plate reader at $405 \mathrm{~nm}$ with $650 \mathrm{~nm}$ as the correction wavelength. Concentrations of the cytokines TNF- $\mathrm{a}$, IFN- $y$, IL-4, IL-10, IL-1ß and IL-13 were estimated using standard curves established with the appropriate recombinant cytokines. The results were expressed as $\mathrm{pg} / \mathrm{mg}$ of total proteins.

\section{Statistical analysis}

Differences among groups were analyzed using GraphPad Prism 6.00 software (GraphPad Software Inc., San Diego USA) by one-way analysis of variance (ANOVA). Results were expressed as means \pm SEM. $p<$ 0.05 was considered statistically significant.

\section{Results}

\section{Histological disorganization of GV-injected mice spleen tissue}

First, we checked the histology of mice spleen, the site of innate and adaptive immune processes [23], after GV injection. Compared to controls (Fig. 1A, B), which did not show any significant changes in spleen tissue histology, we found that spleens from GV-injected mice (Fig. 1C) show indeed remarkable histological changes. In fact, we reported the presence of megacaryocytes (Fig. $1 \mathrm{C}_{1}$ ) with polynuclear inflammatory infiltration (Fig. $1 \mathrm{C}_{3}$ ) in GV-injected mice spleen tissue. In addition, slight extension in red pulps (Fig. $1 \mathrm{C}_{4}$ ) and enlarged lymphoid follicles with aggregates of monocyte-like cells (Fig. ${ }^{1} \mathrm{C}_{2}$ ) were remarked. Together, these findings show that GV injection induce spleen histological disorganization, which suggest an immunomodulatory effect of GV.

\section{Proinflammatory cytokines levels are decreased in GV- treated mice}

Next, we dissected the immunomodulatory effect of GV by investigating changes in pro- and antiinflammatory cytokine levels in mice spleens after GV intraperitoneal injection. Compared to controls, results show that GV-injected mice show a significant decrease in interleukin-1 $\beta$ (IL-1 $\beta$ ) levels, a key mediator of the inflammatory response [24] (Fig. 2A). Tumor necrosis factor alpha (TNF-a) levels showed also a significant decrease in GV-injected mice (Fig. 2B). TNF-a is a multifunctional cytokine secreted primarily by macrophages, natural killer (NK) cells, and lymphocytes; therefore, holds diverse proinflammatory actions [25]. Given that both downregulated cytokines (IL-1 $\beta$ and TNF- $\alpha$ ) are key mediators of pro-inflammatory response, these results suggest that GV negatively affects proinflammatory cytokines levels. 


\section{IFN-y concentration is upregulated upon GV injection}

GV-treated mice showed increased interferon gamma (IFN- $\gamma$ ) level that was 4.5-fold higher in GVinjected than control mice (Fig. 2C). Interestingly, IFN-y has dual role in inflammation. In fact, IFN- $\gamma$ is not only associated with the pathogenesis of chronic inflammatory; but it can also induce anti-inflammatory molecules and modulates pro-inflammatory cytokine production [26]. Taken with proinflammatory cytokines decrease (IL-1 $\beta$ and TNF-a), our findings suggest that upregulation of IFN- $\gamma$ is more likely in favor of regulating pro-inflammatory cytokine levels and promotes anti-inflammatory cytokines secretion.

\section{GV increases anti-inflammatory cytokines levels in the spleen of mice}

To check whether GV immunomodulatory effect affects anti-inflammatory cytokines, interleukin-4 (IL-4), interleukin-10 (IL-10), and interleukin (IL-13) levels were quantified in GV-treated mice. Our results show a significant increase ( 2-fold, $p<0.01)$ in IL-4 concentration (Fig. 2D); however, IL-10 and IL-13 levels remain unchanged between GV-injected and control mice (Fig. 2E, F). These findings show that GV indeed induce anti-inflammatory response and selectively increase IL-4, but not IL-10 nor IL-13 levels.

\section{Discussion}

Immunomodulation refers to the regulation of the immune response by suppressing or enhancing its components for therapeutic purposes [27-29]. Since cytokines are key components of immune response, altering released cytokines concentration will have immediate effects on the immune response. This strategy, termed immunotherapy, is used for the treatment of infections, autoimmune diseases, and cancer, and rely on chemical and biological molecules developed by pharmaceutical companies [30]. Among chemical compounds, triphenylmethane dyes have shown anti-inflammatory activities [31].

Gentian Violet (GV) is a triphenylmethane industrial dye that is known for its antibacterial, antiviral, antihelminthic and anti-tumor effects [4, 5]. This work constitutes the first in vivo study highlighting the immunomodulatory effect of gentian violet. Herein, we show that gentian violet modulates cytokines level in mice spleen. In fact, while pro-inflammatory cytokines (IL-1 $\beta$, TNF- $\alpha$ ) levels are decreased, antiinflammatory cytokine IL-4, and IFN- $\gamma$, an inducer of anti-inflammatory molecules and modulator of proinflammatory cytokine production, are upregulated. In addition, observed changes in GV-treated mice spleen histology that are characterized by the presence of inflammation, infiltration and hyperplastic lymphoid follicles emphasize the immunomodulatory role of gentian violet. This activity could be of interest in studies aiming to develop cancer treatment strategies. As such, studies on animal models described cytokines' roles in the pathogenesis of angiogenesis. IL-1 $\beta$ and TNF- $\alpha$ are potent proangiogenic cytokines, while IL-4 are anti-angiogenic cytokines [32,33]. The ability of gentian violet to increase IL- 4 and decrease IL- $1 \beta$ and TNF- $a$ levels warrant further studies investigating the antiangiogenic potential of gentian violet in cancer treatment. In agreement with this hypothesis, IL-4 can exhibit an anti-tumor activity, as it is involved in promoting immune response against tumor models 
including renal cancer, colorectal cancer, spontaneous adenocarcinoma, colon carcinoma, fibrosarcoma and melanoma $[34,35]$.

Despite the fact that IL-13 shares many biologic activities with IL-4, the insensitivity of IL-13 levels to gentian violet treatment could be explained by the different T-cell subsets that produce IL-13, which may not be affected by gentian violet treatment. Alternatively, since IL-13 secretion requires $\mathrm{CD} 4^{+} \mathrm{T}$ cells differentiation into Th2 cells in the presence of IL-4 [36-38], IL-13 levels may increase later as a consequence of IL-4 upregulation. Contrarily to Humans, where IL-4 inhibits IFN-y secretion [39, 40], in mice, IL-4 is known to enhance IFN- $\gamma$ secretion in response to a variety of stimuli [41]. These findings are in agreement with ours showing an increase in IFN- $y$ levels in GV-treated mice. On the other hand, IL-4, IL10 , and IL-13 were previously shown to inhibit the production of IL-1 $\beta$ and tumor necrosis factor-a [42], which is comparable to our findings showing an increase in IL-4 along with a decrease in IL-1 $\beta$ and TNF$a$. These findings suggest that IL- $1 \beta$ and TNF- $\alpha$ levels decrease could be mediated by IL-4 level increase. In fact, it is known that IL-4 plays a crucial role in shaping the nature of immune responses [43] and that IL-4 production is triggered in response to receptor activation by TH2-type CD $4+\mathrm{T}$ cells, basophils, and mast cells [44]. Since gentian violet significantly upregulates IL-4 levels, it is likely to suggest that this dye can activate IL-4-dependant adaptive immune system represented by naïve CD $4+T$ cells differentiation into Th2 cells [36]. Given the importance of IL-4 in shaping the immune system and disease emergence [43], our findings highlight the importance of depicting the mechanism by which gentian violet triggers IL4 upregulation and its possible beneficial applications.

\section{Conclusion}

The present study demonstrates that Gentian Violet can act as an immumomodulator in rodent model, which favors anti-inflammation by downregulating pro-inflammatory cytokines levels and upregulating anti-inflammatory cytokines and modulator of pro-inflammatory cytokine production. These findings warrant further studies understanding the mechanism by which Gentian Violet modulate the immune system and investigating its potential in developing new therapies.

\section{Declarations}

\section{Ethical Approval and Consent to participate}

The authors certify that all animals were handled and experimental procedures of this work were carried out according to the guidelines of the Institutional Animal Care and Use Committee at the University of Balamand, with strict adherence to the ethical guidelines for the study of experimental pain in conscious animals (Zimmermann, 1983).

Consent to participate: not applicable.

\section{Consent for publication}


Not applicable.

\section{Availability of supporting data}

The authors confirm that the data supporting the findings of this study are available within the article

\section{Competing interests}

The authors have no conflicts of interest to declare.

\section{Funding}

This research was funded by University of Balamand.

\section{Author's Contributions}

Author Contributions: M.K. conceived and designed the experiments; S.J. performed the experiments; A.R.A. and A.I.B. contributed to histopathological study; S.J., M.R., Z.F. and M.K. interpreted the results; J.F., M.R., Z.F. and M.K. wrote the manuscript.

\section{Acknowledgements}

The authors would like to thank Mr. Michek Zakhem and Mrs. Takla El Khoury for their technical help.

\section{Authors information}

Salam Jbeili ${ }^{a,+}$, Mohamad Rima $^{\mathrm{b},+}$, Abdul Rahman Annous $^{c}$, Abdo Ibrahim Berroc ${ }^{c}$, Ziad Fajloun ${ }^{\mathrm{d}, \mathrm{e}}$, Marc Karam $^{\mathrm{a}, *}$

a Department of Biology, University of Balamand, Kalhat, Al-Kurah, P.O. box 100 Tripoli, Lebanon;

b Institut de Génétique et de Biologie Moléculaire et Cellulaire (IGBMC), INSERM U964, CNRS U7104, Université de Strasbourg, 67400 Illkirch, France;

${ }^{\mathrm{c}}$ Medical Laboratory, Faculty of Health Sciences, University of Balamand

d Laboratory of Applied Biotechnology (LBA3B), Azm Center for Research in Biotechnology and its Applications, Doctoral School for Sciences and Technology, Lebanese University, El Mittein Street, 1300 Tripoli, Lebanon;

e Faculty of Sciences 3, Lebanese University, Michel Slayman Tripoli Campus, Ras Maska 1352, Lebanon.

\section{References}


1. Zucca P, Cocco G, Sollai F, Sanjust E. Fungal laccases as tools for biodegradation of industrial dyes. Biocatalysis. 2016;1(open-issue):82-108.

2. Thetford D. Triphenylmethane and Related Dyes. In: Kirk-Othmer Encyclopedia of Chemical Technology. Hoboken: John Wiley \& Sons, Inc.; 2013.

3. Lauth C. On the new aniline dye, Violet de paris. Laboratory. 1867;1:138-9.

4. Maley AM, Arbiser JL. Gentian Violet: a 19th century drug re-emerges in the 21 st century. Exp Dermatol. 2013;22(12):775-80.

5. Conn HJ. An investigation of American gentian violets: Report of Committee on Bacteriological Technic. J Bacteriol. 1922;7(5):529.

6. de Souza Pietra RCC, Rodrigues LF, Teixeira E, Fried L, Lefkove B, Rabello A, et al Triphenylmethane Derivatives Have High In Vitro and In Vivo Activity against the Main Causative Agents of Cutaneous Leishmaniasis. Giorgio S, editor. PLoS One. 2013 Jan;8(1):e51864.

7. Berrios RL, Arbiser JL. Effectiveness of gentian violet and similar products commonly used to treat pyodermas. Dermatol Clin. 2011;29(1):69-73.

8. Aljofan M, Sganga ML, Lo MK, Rootes CL, Porotto M, Meyer AG, et al. Antiviral activity of gliotoxin, gentian violet and brilliant green against Nipah and Hendra virus in vitro. Virol J. 2009;6(1):187.

9. Liu W, Chao Y, Yang X, Bao H, Qian S. Biodecolorization of azo, anthraquinonic and triphenylmethane dyes by white-rot fungi and a laccase-secreting engineered strain. J Ind Microbiol Biotechnol. 2004;31(3):127-32.

10. Azmi W, Sani RK, Banerjee UC. Biodegradation of triphenylmethane dyes. Enzyme Microb Technol. 1998;22(3):185-91.

11. Au W, Pathak S, Collie CJ, Hsu TC. Cytogenetic toxicity of gentian violet and crystal violet on mammalian cells in vitro. Mutat Res Toxicol. 1978;58(2-3):269-76.

12. Gill P, Arora D, Chander M. Biodecolourization of azo and triphenylmethane dyes by Dichomitus squalens and Phlebia spp. J Ind Microbiol Biotechnol. 2002 Apr;28(4):201-3.

13. LITTLEFIELD N. Chronic toxicity and carcinogenicity studies of gentian violet in mice. Fundam Appl Toxicol. 1985 Oct;5(5):902-12.

14. Jurevic RJ, Traboulsi RS, Mukherjee PK, Salata RA, Ghannoum MA. Identification of gentian violet concentration that does not stain oral mucosa, possesses anti-candidal activity and is well tolerated. Eur J Clin Microbiol Infect Dis. 2011 May;30(5):629-33.

15. Vousden KH, Lane DP. p53 in health and disease. Nat Rev Mol cell Biol. 2007;8(4):275-83.

16. Schuler M, Green DR. Transcription, apoptosis and p53: catch-22. Trends Genet. 2005;21(3):182-7.

17. Yamaguchi M, Vikulina T, Weitzmann MN. Gentian violet inhibits MDA-MB-231 human breast cancer cell proliferation, and reverses the stimulation of osteoclastogenesis and suppression of osteoblast activity induced by cancer cells. Oncol Rep. 2015;34(4):2156-62.

18. Mukawera E, Chartier S, Williams V, Pagano PJ, Lapointe R, Grandvaux N. Redox-modulating agents target NOX2-dependent IKKE oncogenic kinase expression and proliferation in human breast cancer 
cell lines. Redox Biol. 2015 Dec;6:9-18.

19. Lawrence T. The Nuclear Factor NF- B Pathway in Inflammation. Cold Spring Harb Perspect Biol. 2009 Dec;1(6):a001651-1.

20. Zimmermann M. Ethical guidelines for investigations of experimental pain in conscious animals. Pain. 1983;16(2):109-10.

21. Ibrahim K, Al-Mutary M, Bakhiet A, Khan H. Histopathology of the Liver, Kidney, and Spleen of Mice Exposed to Gold Nanoparticles. Molecules. 2018 Jul;23(8):1848.

22. Dey P. Tissue Microtomy: Principle and Procedure. In: Basic and Advanced Laboratory Techniques in Histopathology and Cytology. Singapore: Springer Singapore; 2018. pp. 41-50.

23. Wluka A, Olszewski WL. Innate and adaptive processes in the spleen. Ann Transplant. 2006;11(4):22-9.

24. Lopez-Castejon G, Brough D. Understanding the mechanism of IL-1 $\beta$ secretion. Cytokine Growth Factor Rev. 2011 Aug;22(4):189-95.

25. Chu W-M. Tumor necrosis factor. Cancer Lett. 2013 Jan;328(2):222-5.

26. Mühl H, Pfeilschifter J. Anti-inflammatory properties of pro-inflammatory interferon-y. Int Immunopharmacol. 2003 Sep;3(9):1247-55.

27. Zhao X, Li R, Huang J, Li J, Hou M, Zhong J. Association of some physiological factors and milk performance in Chinese Holstein. Asian J Anim Vet Adv. 2012;7(12):1356-63.

28. Fraile L, Crisci E, Córdoba L, Navarro MA, Osada J, Montoya M. Immunomodulatory properties of beta-sitosterol in pig immune responses. Int Immunopharmacol. 2012;13(3):316-21.

29. Chauhan RS. Nutrition, immunity and livestock health. Indian Cow Sci Econ J. 2010;7(24):2-13.

30. Zhang J-M, An J. Cytokines, Inflammation, and Pain. Int Anesthesiol Clin. 2007;45(2):27-37.

31. Bonner MY, Arbiser JL. Targeting NADPH oxidases for the treatment of cancer and inflammation. Cell Mol life Sci. 2012;69(14):2435-42.

32. Naldini A, Carraro F. Role of inflammatory mediators in angiogenesis. Curr Drug TargetsInflammation Allergy. 2005;4(1):3-8.

33. Hong K-H, Cho M-L, Min S-Y, Shin Y-J, Yoo S-A, Choi J-J, et al. Effect of interleukin-4 on vascular endothelial growth factor production in rheumatoid synovial fibroblasts. Clin Exp Immunol. 2007 Mar;147(3):573-9.

34. Li Z, Chen L, Qin Z. Paradoxical Roles of IL-4 in Tumor Immunity. Cell Mol Immunol. 2009 Dec;6(6):415-22.

35. Shurin MR, Lu L, Kalinski P, Stewart-Akers AM, Lotze MT. Th1/Th2 balance in cancer, transplantation and pregnancy. In: Springer seminars in immunopathology. Springer; 1999. p. 339-59.

36. Yoshimoto T. The Hunt for the Source of Primary Interleukin-4: How We Discovered That Natural Killer T Cells and Basophils Determine T Helper Type 2 Cell Differentiation In Vivo. Front Immunol. 2018 Apr 23;9. 
37. Junttila IS. Tuning the Cytokine Responses: An Update on Interleukin (IL)-4 and IL-13 Receptor Complexes. Front Immunol. 2018 Jun 7;9.

38. Bao K, Reinhardt RL. The differential expression of IL-4 and IL-13 and its impact on type-2 immunity. Cytokine. 2015 Sep;75(1):25-37.

39. Brinkmann V, Geiger T, Alkan S, Heusser $\mathrm{CH}$. Interferon alpha increases the frequency of interferon gamma-producing human CD4 + T cells. J Exp Med. 1993;178(5):1655-63.

40. Peleman R, Wu J, Fargeas C, Delespesse G. Recombinant interleukin 4 suppresses the production of interferon gamma by human mononuclear cells. J Exp Med. 1989;170(5):1751-6.

41. Lai KN, Leung JCK, Li PKT, Lui SF. Cytokine production by peripheral blood mononuclear cells in IgA nephropathy. Clin Exp Immunol. 1991;85(2):240-5.

42. Morita $Y$, Yamamura $M$, Kawashima M, Aita T, Harada S, Okamoto $H$, et al. Differential in vitro effects of IL-4, IL-10, and IL-13 on proinflammatory cytokine production and fibroblast proliferation in rheumatoid synovium. Rheumatol Int. 2001 Feb;6(2):49-54. 20(.

43. Choi P, Reiser H. IL-4: role in disease and regulation of production. Clin Exp Immunol. 1998 Sep;113(3):317-9.

44. Legård GE, Pedersen BK. Muscle as an Endocrine Organ. In: Muscle and Exercise Physiology. Elsevier; 2019. p. 285-307.

\section{Figures}




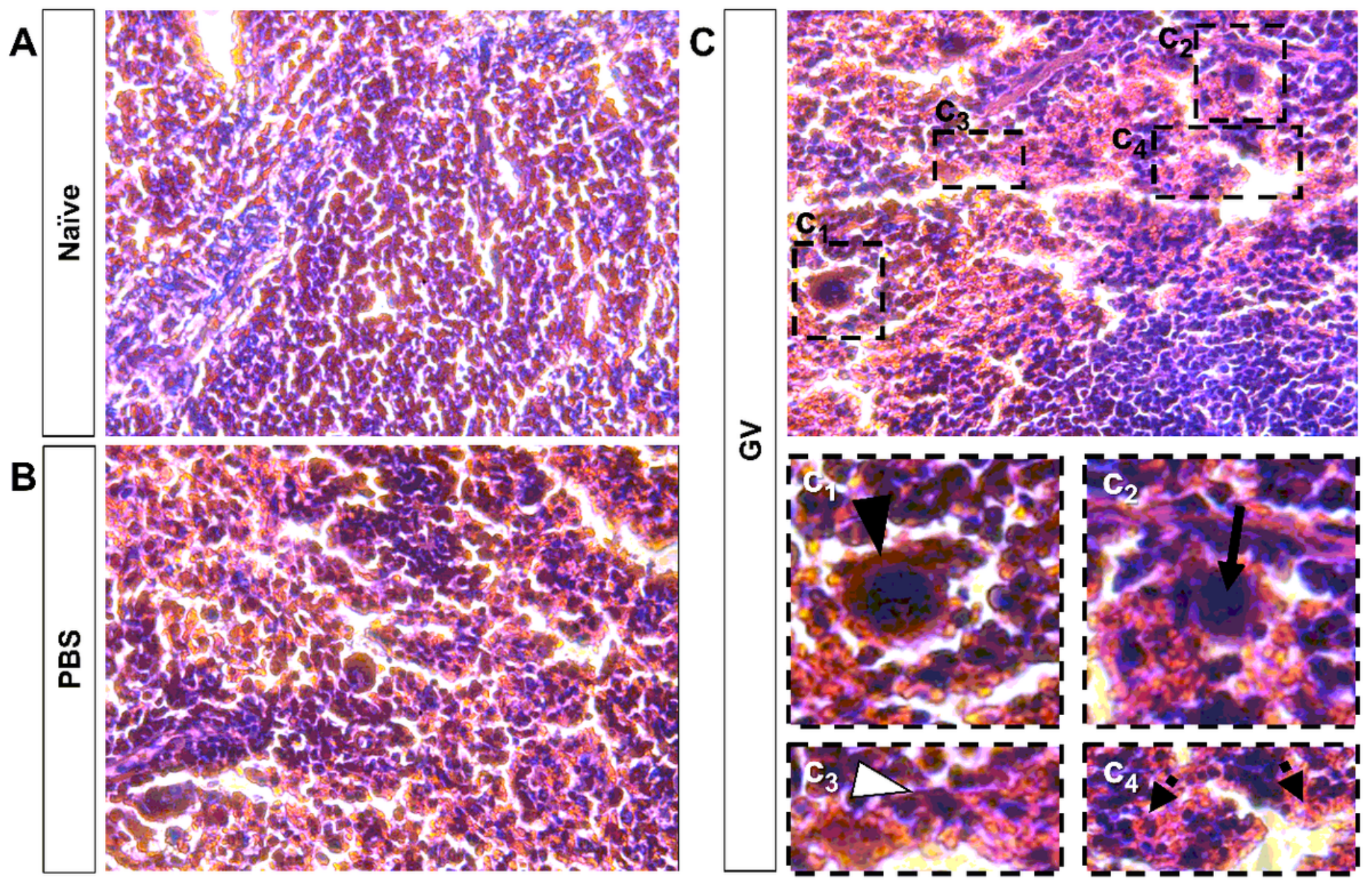

\section{Figure 1}

Histological changes are observed in spleen tissue of GV-injected mice. Microscopic observations and histological evaluation of spleen tissue from (A) naïve, (B) PBS-, and (C) GV-injected mice. While (A) naïve and (B) PBS-injected mice don't show major spleen histological changes, (C) GV-injected mice show megakaryocytes (C1), enlarged lymphoid follicles (C2), polynuclear inflammatory infiltration (C3), and extension in red-pulps (C4) in spleen tissue. 
A

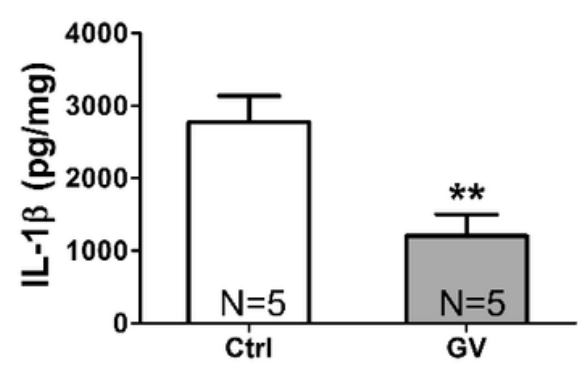

D

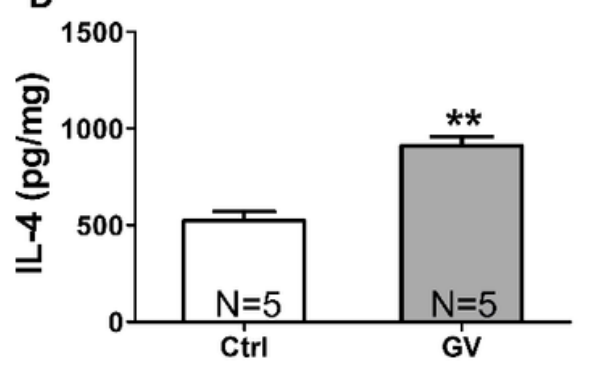

B

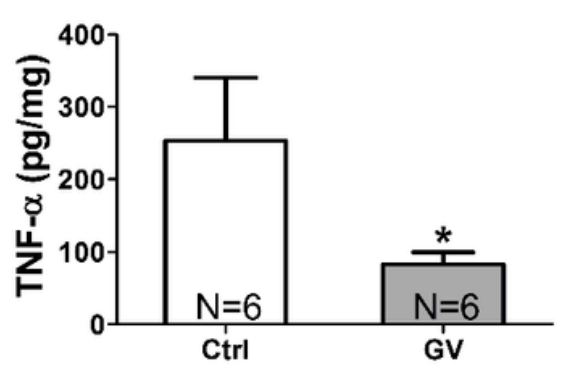

E

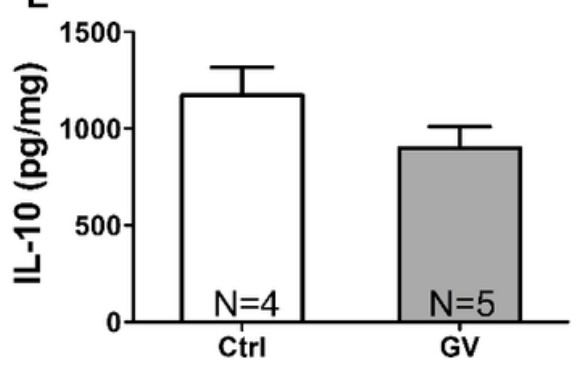

C

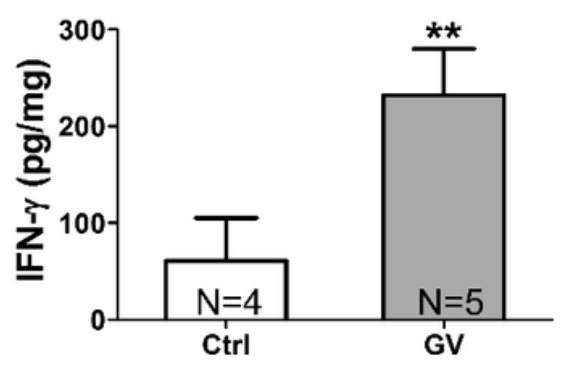

$\mathbf{F}$

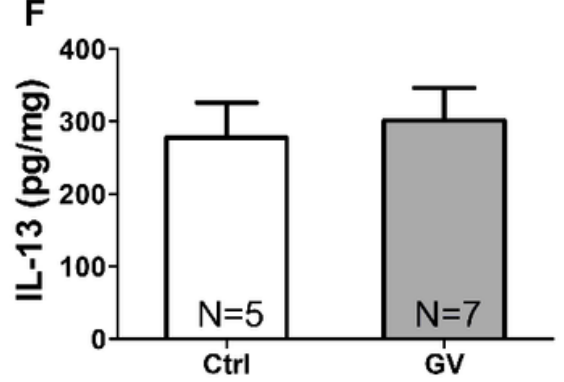

Figure 2

GV modulates cytokines levels in the spleen. Levels of (A) IL-1 $\beta$, (B) TNF- $\alpha$, (C) IFN- - , (D) IL-4, (E) IL-10, and $(F)$ IL-13 were measured using an enzyme-linked immunosorbent assay kit (ELISA). * $p<0.05$, ** p<0.01. IL-1 $\beta$ : Interleukin-1 $\beta$, TNF-a: Tumor necrosis factor alpha, IFN- $\gamma$ : Interferon gamma, IL-4: Interleukin-4, IL-10: Interleukin-10, IL-13: Interleukin-13. 